\title{
Radio Studies of the High-Latitude Ionosphere During the Solar Eclipse of 20 July 1963
}

\author{
Robert D. Hunsucker ${ }^{1}$ \\ Contribution From the Geophysical Institute, University of Alaska, College, Alaska
}

(Received June 10, 1964; revised September 17, 1964)

\begin{abstract}
An investigation of the effects of the total solar eclipse of 20 July 1963 on the highlatitude ionosphere was conducted at various locations in Alaska. Simultaneous observations of $\mathrm{HF}$ forward propagation and vertical incidence sounder measurements of various ionospheric parameters indicated marked changes in $E$ - and $F$ 1-layer critical frequencies and virtual heights during the eclipse.

Riometer measurements of absorption of $27 \mathrm{Mc} / \mathrm{s}$ were made at Tonsina, Ft. Yukon, and College, Alaska and eclipse effects were observed at all three stations. Because of auroral corpuscular precipitation effects and the difficulty in obtaining an accurate quiet day curve, it was very difficult to determine quantitative $D$-region effects due to the eclipse.
\end{abstract}

\section{Introduction}

The solar eclipse of 20 July 1963 afforded an excellent opportunity to study radio propagation and absorption effects in the high-latitude ionosphere. The optical eclipse occurred at approximately 1000 , $150^{\circ}$ WMT on 20 July at an elevation angle of $44^{\circ}$ as seen from the town of Sourdough, Alaska.

An exhaustive coverage of previous radio eclipse investigations may be found in the book "Solar Eclipses and the Tonosphere" edited by W. J. B. Beynon and G. M. Brown [1955]. The only previous thorough investigation of solar eclipse effects on the auroral ionosphere was conducted during the solar eclipse of 30 June 1954. Davies [1955] devoted special attention to vertical sweep-frequency ionospheric soundings and absorption measurements using the pulse reflection technique. The results of these earlier investigations indicated that the greatest effects occurred in the F1-layer. The $E$ - and $D$-layers also showed pronounced eclipse effects, and evidence of a corpuscular eclipse preceding the optical eclipse by four hours was presented. The eclipse effects of the $F$ 2-layer were reported to be very difficult to ascertain because of the spread of the echoes and blanketing effects by lower layers.

\section{Results of the Present Investigation}

The investigation of the 20 July eclipse reported herein is based on simultaneous observation of ionospheric eclipse effects by three methods:

(1) Measurement at College, Alaska, of forwardpropagated HF signal strength from WWVH.

\footnotetext{
1 Present address: National Bureau of Standards, Boulder, Colo.
}

(2) Vertical ionospheric soundings from Anchorage.

(3) Riometer measurements of $27.6 \mathrm{Mc} / \mathrm{s}$ cosmic radio noise from locations near the auroral zone.

The map in figure 1 shows the entire path of totality in relation to the maximum auroral zone, after Vestine [1944]. The approximate antenna pattern of a step-frequency sounder utilized in another experiment, and the HF great circle propagation path between Hawaii and College, Alaska, are also illustrated. Figure 2 gives a detailed picture of the totality path and the auroral zone. The location of the Anchorage vertical ionosonde and riometer and the half-power pattern of the Tonsina, College, and Ft. Yukon riometers at 100 $\mathrm{km}$ height are also shown.

\subsection{Simultaneous HF Signal Strength and Vertical Ionosonde Studies}

The 10 and $15 \mathrm{Mc} / \mathrm{s}$ transmissions from WWVH in Hawaii were monitored at the College Minitrack station during the period 20-21 July 1963. Monitoring equipment consisted of a 3-element Yagi antenna on each frequency feeding $\mathrm{R}-390$ receivers whose AGC outputs were recorded on a Sanborn recorder.

The audio output of the $\mathrm{R}-390$ receivers was also displayed on a dual trace oscilloscope. Thus, information on the relative time delay of the WWVH 10 and $15 \mathrm{Mc} / \mathrm{s}$ signals was available.

$\mathrm{C}-3$ vertical soundings and $30 \mathrm{Mc} / \mathrm{s}$ riometer data were also available from the NBS North Pacific Radio Warning Service in Anchorage during the eclipse period. Figure 3 shows typical 2- and 3-hop $F$-layer modes for the Hawaii-College great circle propagation path in relation to the eclipse shadow. 


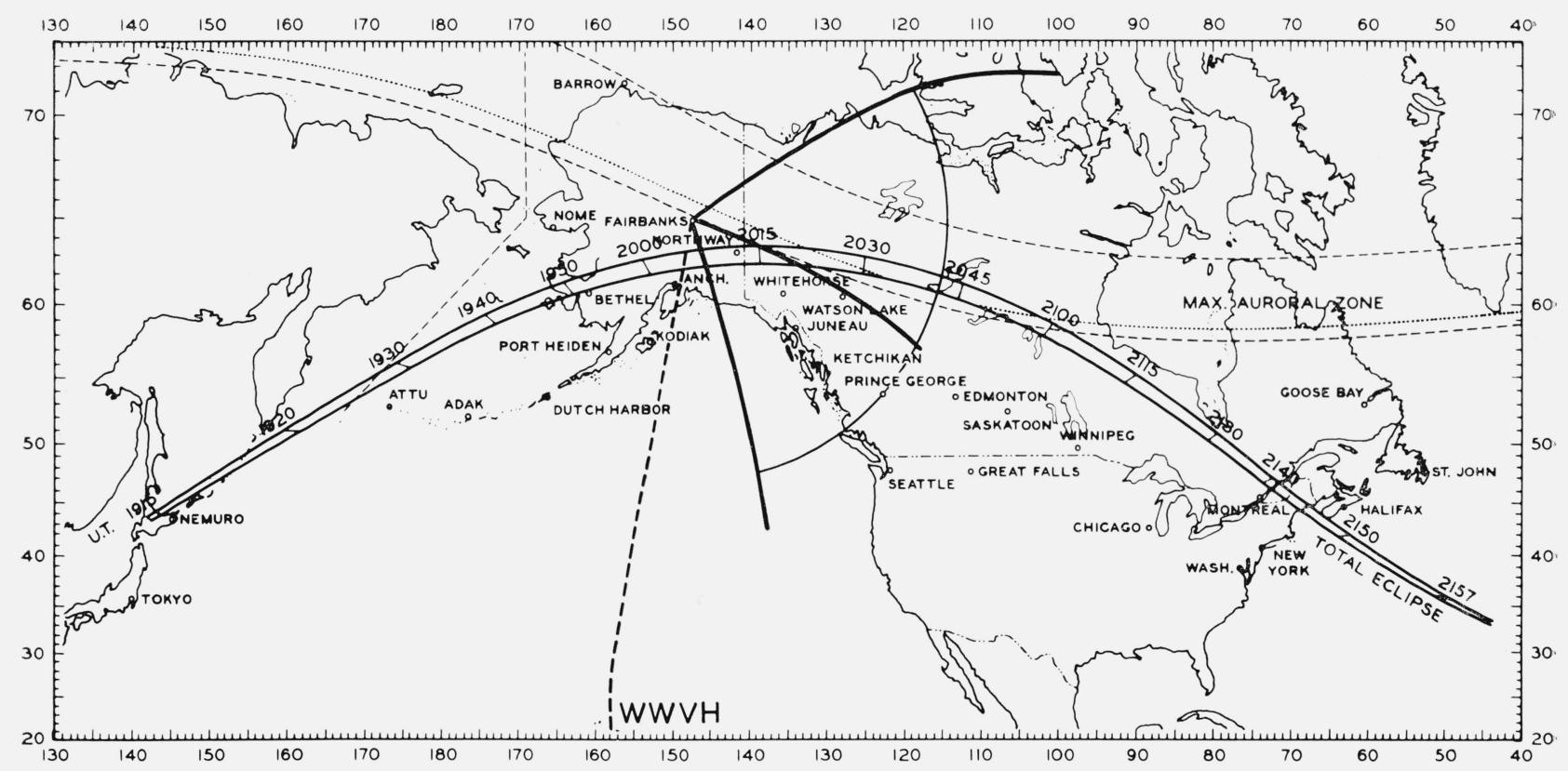

Figure 1. Map showing entire path of totality in relation to auroral zone and Hawaii-College great circle propagation path.

The Anchorage installation primarily observes the ionospheric $D, E$, and $F 1$-regions in the eclipse shadow.

Figure 4 shows the WWVH 10 and $15 \mathrm{Mc} / \mathrm{s}$ signal strength along with the Anchorage C-3 and riometer data. The arrows indicate times of first contact, last contact, and totality for the various layer heights. At 2002 U'T the $10 \mathrm{Mc} / \mathrm{s}$ WWVH signal amplitude dropped $15 \mathrm{~dB}$ while the $15 \mathrm{Mc} / \mathrm{s}$ signal level remained essentially unchanged. The signal strength recording ceased at 2015 U'T when the receiving antenna was rotated.

The Anchorage C-3 sounder indicated that the major changes occurred in the $E$ and $F 1$ layers. The F1-layer data are incomplete around totality time due to a weak trace on the recording oscilloscope caused by a low voltage condition when the equipment was running continuously. The E-layer critical frequency $\left(f_{0} E\right)$ dropped from a pre-eclipse value of $2.8 \mathrm{Mc} / \mathrm{s}$ to $1.6 \mathrm{Mc} / \mathrm{s}$ at totality, while $f_{\mathrm{o}} \mathrm{F} 2$ increased from 4.5 to $5.6 \mathrm{Mc} / \mathrm{s}$. The virtual height of the E-layer remained essentially constant while there were indications that the $F 1$ layers merged at approximately $250 \mathrm{~km}$. The absorption effects indicated by the $f_{\min }$ and $30 \mathrm{Mc} / \mathrm{s}$ riometer data are not pronounced during the eclipse. The Anchorage riometer utilized a very wide-beam antenna. Data acquired by the $\mathrm{C}-3$ ionosonde at College $(200 \mathrm{~km}$ north of the eclipse shadow) were also analyzed, but no pronounced eclipse effects were observed.

The relative time delays between the 10 and 15 $\mathrm{Mc} / \mathrm{s}$ WWVH signals during the eclipse are shown in a sequence of Polaroid photographs of the dual-trace oscilloscope in figure 5. Both traces are offset for the propagation time on the Hawaii-College circuit and are triggered by the 1 pulse/sec ouptut of the Minitrack time standard. The $15 \mathrm{Mc} / \mathrm{s}$ time "tick" remained fixed in time throughout the duration of the eclipse, while the $10 \mathrm{Mc} / \mathrm{s}$ "tick" shifted 1 msec at 2001:00 U'T and showed erratic variation for the remainder of the eclipse period.

Summary of $H F$ reception and $C-3$ sounding data. The results of the simultaneous WWVH reception and $\mathrm{C}-3$ vertical ionosonde investigations during the eclipse are summarized below:

(i) A sharp $(15 \mathrm{~dB})$ decrease in the $10 \mathrm{Mc} / \mathrm{s}$ WWVH signal amplitude at totality.

(ii) No marked deterioration of the $15 \mathrm{Mc} / \mathrm{s}$ WWVH signal amplitude at totality.

(iii) A pronounced variation in the propagation time of the $10 \mathrm{Mc} / \mathrm{s}$ signal at totality while the $15 \mathrm{Mc} / \mathrm{s}$ signal propagation time remained constant.

(iv) Negligible absorption effects indicated by $f_{\min }$ and $30 \mathrm{Mc} / \mathrm{s}$ riometer data at Anchorage.

(v) A large change in $f_{0} E$ and $f_{0} F 1$ during totality.

In view of the foregoing results, it is most probable that the $10 \mathrm{Mc} / \mathrm{s}$ WWVH signal changed to a less favorable mode at totality. Probably an $E$ or $F 1$ mode was operative for the $10 \mathrm{Mc} / \mathrm{s}$ propagation path at the College end of the circuit.

\subsection{6 Mc/s Riometer Measurements of D-Layer Eclipse Effects}

A standard IGY-type $27.6 \mathrm{Mc} / \mathrm{s}$ riometer and antenna [Little and Leinbach, 1959] was operated at Tonsina, Alaska, during the period 15-21 July 1963. 


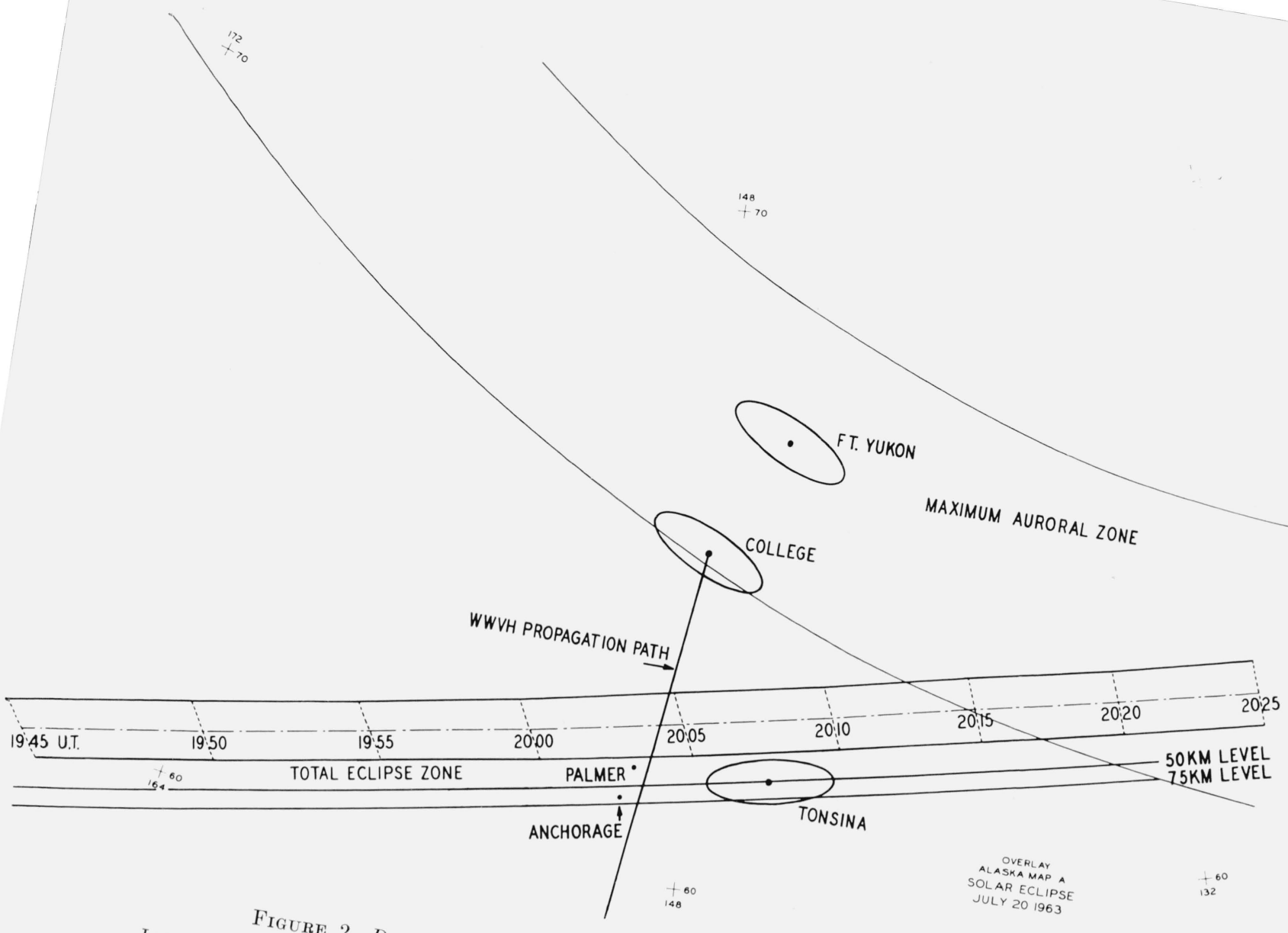

Location of College, Ft. Yukon, Anchorage, and Tonsina observing stations and antion to aroral zone.
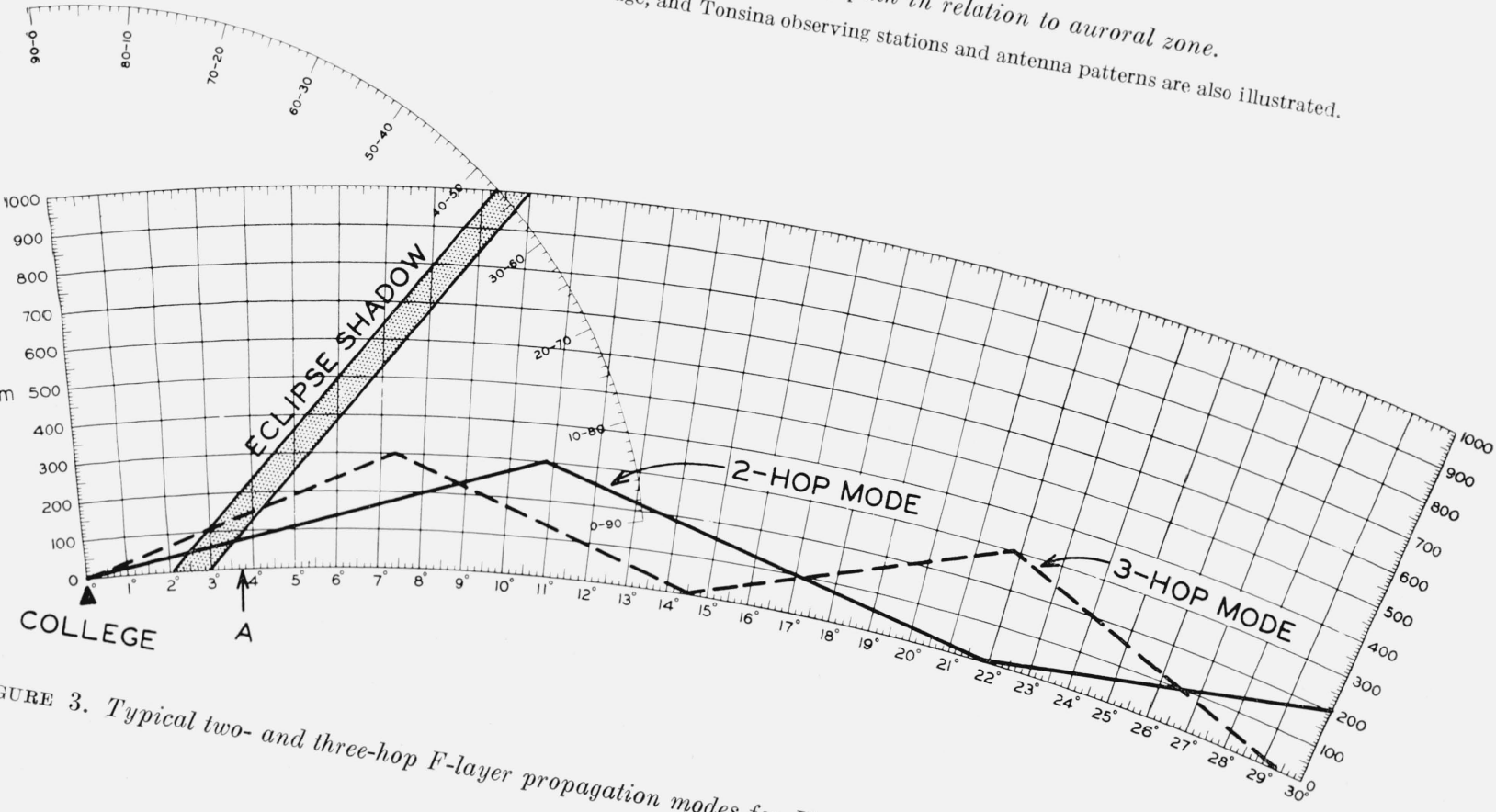


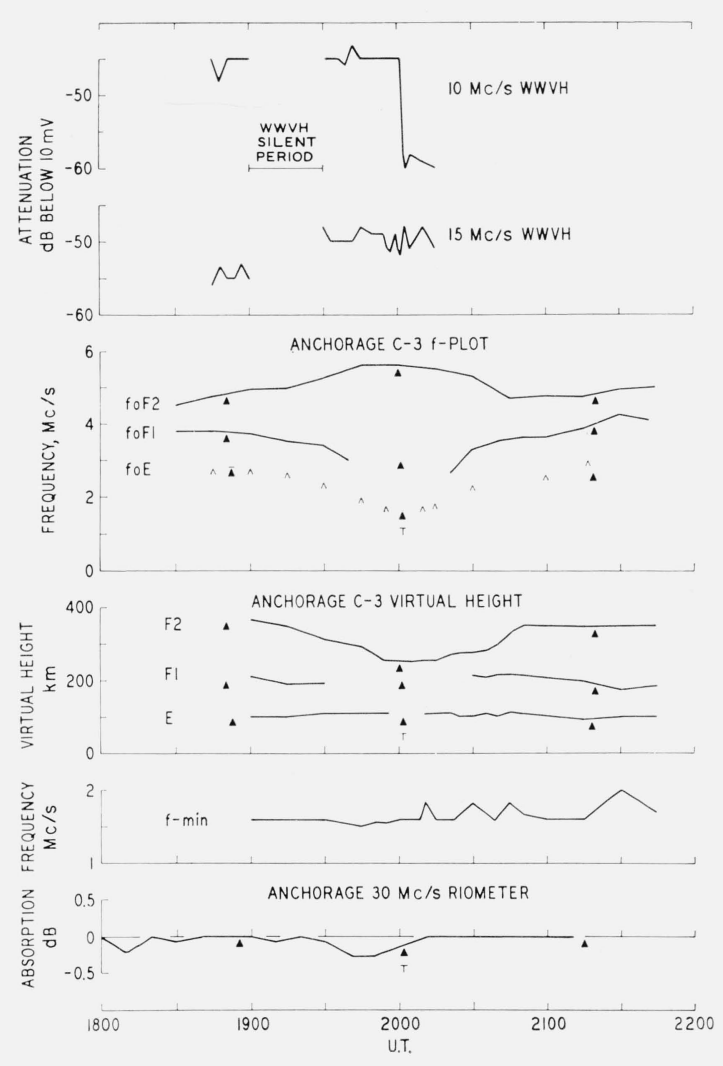

Figure 4. Simultaneous $W W V H$ signal strength, Anchorage ionosonde and riometer data for eclipse period.

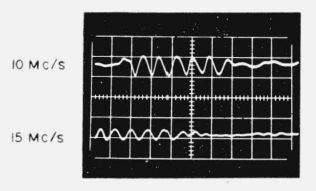

1934:28UT

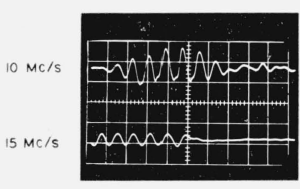

$1940: 48$ UT

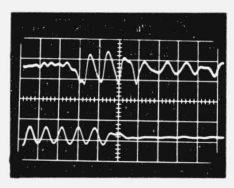

2001:00UT

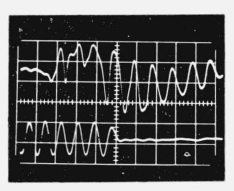

200527 UT

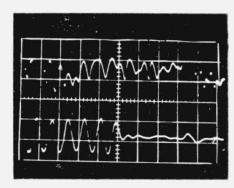

2012:40UT

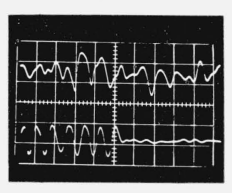

201324 UT
Figure 5. Time-delay variation of WWVH time "ticks" during eclipse.

Tonsina was selected because of its easy accessibility, the availability of electrical power, and its location in relation to the path of totality.

In addition to the Tonsina riometer, data from two $27.6 \mathrm{Mc} / \mathrm{s}$ riometers not in the path of totality were also available (College and Ft. Yukon). Figure 2 shows the ground path of totality and the totality contours for 50 and $75 \mathrm{~km}$ ( $D$ region) heights. The half-power antenna patterns at $100 \mathrm{~km}$ height of the Tonsina, College, and Ft. Yukon riometers are also shown.
An indication of the relative geomagnetic activity for 19,20 , and 21 July is given in table 1, taken from selected geomagnetic data [Lincoln, 1963].

TABLE 1

\begin{tabular}{|c|c|c|c|c|c|}
\hline \multicolumn{6}{|c|}{ July $1963, R_{z}=19.0$} \\
\hline Day & $\Sigma K$ & Prel. $C_{i}$ & $C_{p}$ & $A_{p}$ & Prov. $R_{z}$ \\
\hline $\begin{array}{l}19 \\
20 \\
21\end{array}$ & $\begin{array}{l}10+ \\
12 \\
18\end{array}$ & $\begin{array}{r}0.2 \\
.4 \\
1.2\end{array}$ & $\begin{array}{r}0.2 \\
.3 \\
1.2\end{array}$ & $\begin{array}{r}5 \\
7 \\
26\end{array}$ & $\begin{array}{l}15 q \\
11 \\
19 D\end{array}$ \\
\hline
\end{tabular}

College and Anchorage $K$-indices also indicated that 19 and 20 July were relatively quiet days geomagnetically, while 21 July was quite disturbed. Since the Tonsina riometer was only in operation for a relatively short period, the quiet day curve was based on smoothed values of the 19 July riometer data. Precise quiet day curves were available for the College and Ft. Yukon riometers and absorption values accurate to $\pm 0.10 \mathrm{~dB}$ are probable.

It should be emphasized that, since a precise quiet day curve was not available for the Tonsina riometer, the Tonsina absorption data are of a semiquantitative nature. Absorption values from the Tonsina, College, and Ft. Yukon riometers are shown in figure 6, and all show a rather sharp decrease in absorption near totality. The absorption decrease at Tonsina was more pronounced than at College or Ft. Yukon as would be expected. In fact, it is quite surprising that College and Ft. Yukon should show any eclipse effects since they are quite far removed from the path of totality (see fig. 2). Evaluation of the eclipse effects was complicated by the presence of auroral absorption commencing $6 \mathrm{hr}$ before the eclipse at Tonsina. The auroral absorption was also measured by the College and Ft. Yukon riometers which showed quite good correlation on the absorption peaks.

The sharp decreases of absorption near totality were probably due to recombination in the $D$ region caused by decrease in the solar UV radiation.

There is some indication that the absorption at Tonsina decreased below the quiet day level at totality as would be expected. Because of the lack of a precise quiet day curve and the presence of corpuscular precipitation manifested by the auroral absorption, however, the exact decrease cannot be obtained from the Tonsina data.

Lerfald, Hargreaves, and Watts [1963] conducted an investigation on measurement of D-region absorption during the solar eclipse of 20 July at Palmer, Alaska. Riometer observations at frequencies of 10 and $15 \mathrm{Mc} / \mathrm{s}$ in both the ordinary and extraordinary modes indicated maximum decreases from the normal absorption during the eclipse of $1.5 \mathrm{~dB}$ on the $10 \mathrm{Mc} / \mathrm{s}$ X-mode and $0.4 \mathrm{~dB}$ on the $15 \mathrm{Mc} / \mathrm{s}$ O-mode. The absorption minima occurred within 2 min of totality.

Taking the value of absorption obtained at 10 $\mathrm{Mc} / \mathrm{s}$ by Lerfald et al., and assuming a frequency exponent of 1.7 for auroral zone absorption (Parthasarathy, private communication, 1964), the 

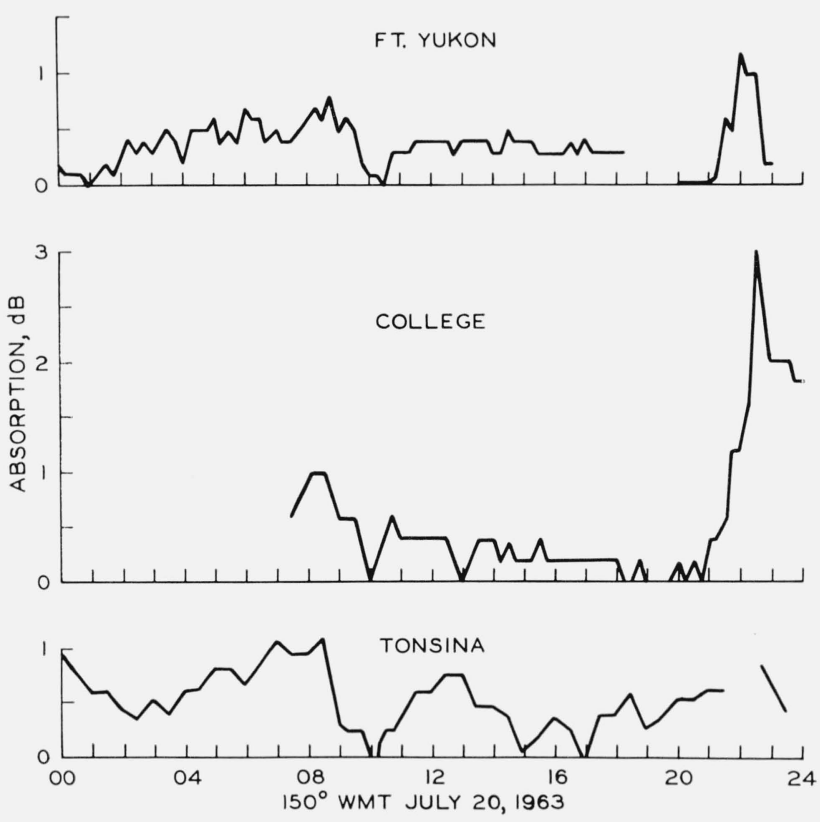

Figure 6. Ft. Yukon, College, and Tonsina $27.6 \mathrm{Mc} / \mathrm{s}$ riometer records for 20 July 1963.

expected value of absorption at $27.6 \mathrm{Mc} / \mathrm{s}$ can be calculated as

$A_{27.6}=A_{10}\left(\frac{10}{27.6}\right)^{1.7}=1.5 \mathrm{~dB}(0.36)^{1.7}$

$$
=1.5(0.18)=0.27 \mathrm{~dB} \text {. }
$$

In order to detect a decrease of absorption of this magnitude at $27.6 \mathrm{Mc} / \mathrm{s}$ an extremely accurate quiet day curve must be utilized. The IGY riometer is, at best, accurate to $\pm 0.10 \mathrm{~dB}$. In a recent paper, Vogan [1964] reported a $0.25 \mathrm{~dB}$ increase in the cosmic noise level of $30 \mathrm{Mc} / \mathrm{s}$ at several Canadian stations during the 20 July 1963 eclipse.

Figure 7 is included to show the relatively good peak-to-peak correlation of absorption between College and Tonsina during the strong auroral absorption event of 21 July. The Tonsina recording ended on 1100, 21 July.

\section{Conclusions}

Analysis of 10 and $15 \mathrm{Mc} / \mathrm{s}$ transmissions on a $4800 \mathrm{~km}$ transmission path (Hawaii-College) during the 20 July 1963 solar eclipse showed that the 10 $\mathrm{Mc} / \mathrm{s}$ signal strength dropped $15 \mathrm{~dB}$ at totality while the $15 \mathrm{Mc} / \mathrm{s}$ signal level remained essentially unchanged. Simultaneous ionosonde observations of the eclipsed portion of the propagation path show decreases in $E$ - and $F 1$-layer critical frequencies and changes in the virtual heights of the $F 1$ and $F 2$ layers during the eclipse. The relative time delays of the 10 and $15 \mathrm{Mc} / \mathrm{s}$ WWVH time "ticks" were also recorded, and revealed a $1 \mathrm{msec}$ shift of the

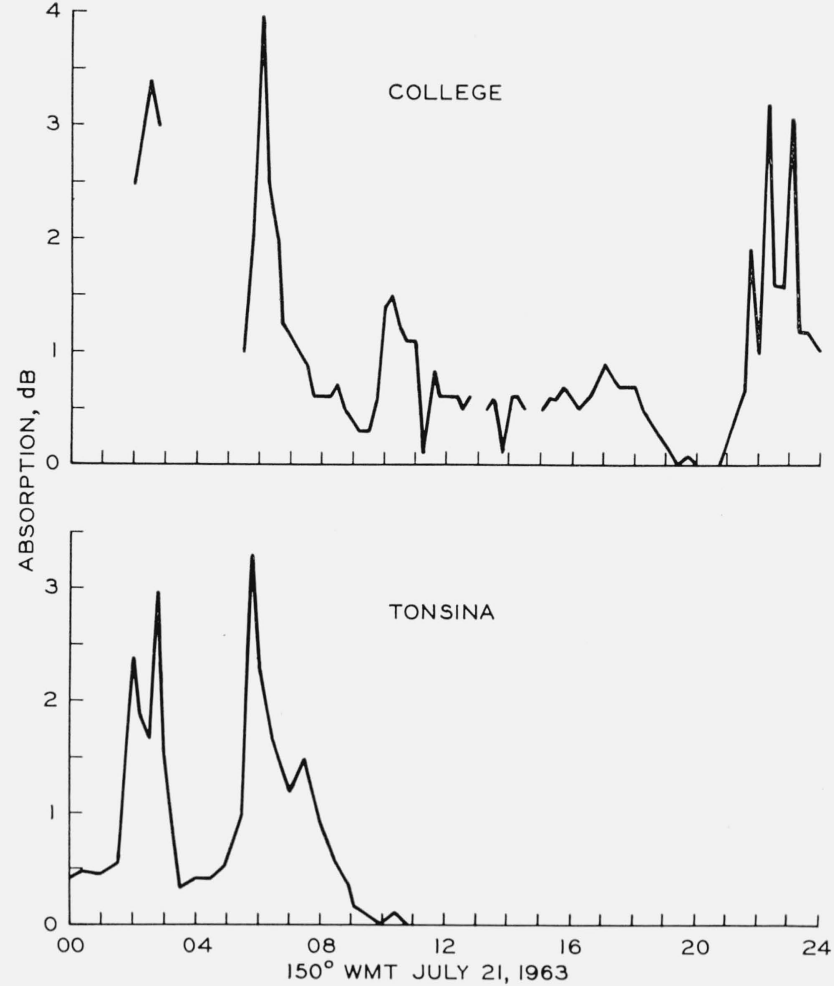

Figure 7. College and Tonsina 27.6 $\mathrm{Mc} / \mathrm{s}$ riometer records for 21 July 1963.

$10 \mathrm{Mc} / \mathrm{s}$ tick while the $15 \mathrm{Mc} / \mathrm{s}$ tick delay remained constant during the eclipse. It is probable that an $E$ or $F 1$ mode was operative for the $10 \mathrm{Mc} / \mathrm{s}$ propagation path at the College end of the circuit and that the $10 \mathrm{Mc} / \mathrm{s}$ signal changed to a less favorable mode at totality.

Observations of solar eclipse effects, utilizing a $27.6 \mathrm{Mc} / \mathrm{s}$ riometer under the eclipse shadow at $D$-region heights were made at Tonsina, Alaska. Other 27.6 Mc/s riometers were operated at College and Ft. Yukon outside the eclipse totality path. Interpretation of these results was complicated by auroral corpuscular precipitation manifested by auroral absorption starting $6 \mathrm{hr}$ before totality at Tonsina. A sharp decrease in the absorption near totality was indicated by all three of the riometers. This decrease was probably due to recombination in the $D$ region caused by a decrease in the solar UV radiation at totality. There is some indication that the absorption at Tonsina decreased below the quiet day level at totality, but the quantitative absorption decrease cannot be obtained because a precise quiet day curve was not available.

Because of the corpuscular precipitation effects and the difficulty in obtaining an accurate quiet day curve, it is very difficult to determine quantitative $D$-region effects due to the eclipse at an auroral zone station utilizing the single-frequency technique. 
I would like to express my appreciation to H. F. Bates, Leif Owren, and R. Parthasarathy of the Geophysical Institute for very helpful discussions pertaining to experimental techniques and analysis of data for this project. R. Franzke and T. Berkey, also of the Geophysical Institute staff, performed valuable service maintaining and operating the riometer. The WWVH monitoring program was made possible through the cooperation of John Miller of the NASA Minitrack station at College. Data from the Anchorage $\mathrm{C}-3$ and riometer were very generously supplied by Mr. Dale Bucknam of the National Bureau of Standards.

This research was supported by the Atmospheric Sciences Section, National Science Foundation, NSF grant GP-1164.

\section{References}

Beynon, W. J. G., and G. M. Brown (Editors) (1955), Solar eclipses and the ionosphere (Pergamon Press, London).

Davies, K., and E. L. Hagg (1955), Ionospheric absorption measurements at Prince Rupert, J. Atmospheric Terrest. Phys., 6, 18.

Lerfald, G., J. K. Hargreaves, and J. M. Watts (1963) Ionospheric absorption at 10 and $15 \mathrm{Mc} / \mathrm{s}$ during the total solar eclipse of July 20, 1963, Paper GA 36 . Presented at AGU Third Western National meeting at Boulder, Colorado, Dec. 26-28, 1963.

Lincoln, J. Virginia (Nov. 15, 1963), Selected Geomagnetic and solar data, J. of Geophys. Res. 68, No. 22, 6200.

Little, C. G., and H. Leinbach (1959), The riometer-a device for the continuous measurement of ionospheric absorption, Proc. IRE 47, No. 2, 315-320.

Vestine, E. H. (1944), The geographic incidence of aurora and magnetic disturbances, northern hemisphere, Terrest. Magnetism Atmospheric Elec. 49, 77-102.

Vogan, E. L. (July, 1964), Absorption measurements during the solar eclipse of July 20, 1963, Can. J. Phys. 42, 13821386 . 